\title{
INTERNET DAN GAYA FASHION MAHASISWA
}

\author{
Prijana \\ Program Studi Ilmu Perpustakaan Universitas Padjadjaran \\ prijana@unpad.ac.id
}

\begin{abstract}
The aim of the research: to know and explain the behavior of shopping on line with the presence of internet campus; know and explain the result of consuming the internet information that is associated with the orientation of the actions symbolically. Research Method: grounded research. Research Results: Students provide the welcoming response of the presence of free internet. They choose to approach the library campus with free internet. The intensity of the visit to the library increased since the presence of free internet. Users like line online for information fashion. User Men prefer merk and newness to select fashion. While user women prefer unique to choose fashion. User men like fashion hair that moderate, such as old school. While user women tend to select hair care and more conservative. Here consumers online have dual needs response. The presence of students as consumers online in the library campus original purpose to do the task - the task lecture and then ( secondary) to shopping online information world fashion. In the habit of behavior ( information behavior ), the destination position can may upside down, even before they were looking for lecture material online, they first need rilek moment (enjoy) with internet browsing activities. They have the level of need, i.e. if an information that is he was looking for it to have the value of the high needs, then they will find the information in more detail, complete, and hunt (Quarry ). If a information while he was looking for it have the value that needs less, so they will search for information hopefully alone without you walk further. They prefer to compare fashion that used in its social environment. Online information about fashion looks powerful and made the primary source of information. While they are rarely use secondary sources of information. In his social environment, they usually prefer a friend that gadgetry and fashionable as a source of information.
\end{abstract}

Keywords: Shoping online, fashionable, internet
ABSTRAK - Tujuan penelitian: untuk mengetahui dan menjelaskan perilaku shopping on line dengan hadirnya internet kampus; mengetahui dan menjelaskan akibat mengkonsumsi informasi internet, yang dikaitkan dengan orientasi tindakan simboliknya. Metode penelitian: grounded research. Hasil penelitian: Mahasiswa memberikan respon welcoming atas kehadiran internet gratis. Mereka memilih untuk mendekat perpustakaan kampus dengan internet gratis. Intensitas kunjungan ke perpustakaan meningkat semenjak hadirnya internet gratis. Users menyukai shoping online untuk informasi fashion. User laki-laki lebih menyukai merk dan newness untuk memilih fashion. Sementara user perempuan lebih menyukai yang unik untuk memilih fashion. User laki-laki menyukai fashion rambut yang moderat, seperti old school. Sementara user perempuan cenderung untuk memilih perawatan rambut dan lebih konservatif. Disini konsumen online memiliki respon kebutuhan ganda. Kehadiran mahasiswa sebagai konsumen online di perpustakaan kampus tujuan awalnya untuk mengerjakan tugas - tugas perkuliahan dan selanjutnya ( secondary) untuk shopping online informasi dunia fashion. Dalam kebiasaan perilakunya ( information behavior ), posisi tujuan bisa mungkin terbalik, yakni sebelum mereka mencari materi perkuliahan online, mereka terlebih dahulu butuh rilek sejenak (enjoy) dengan melakukan aktivitas browsing internet. Mereka memiliki level of need, yakni jika suatu informasi yang sedang ia cari itu memiliki nilai kebutuhan yang tinggi, maka mereka akan mencari informasi itu secara lebih detail, lengkap, dan memburu ( Quarry). Jika suatu informasi yang sedang ia cari itu memiliki nilai kebutuhan yang kurang, maka mereka akan mencari informasi sedapatnya saja tanpa menelusur lebih jauh. Mereka suka membandingkan fashion yang digunakan di lingkungan sosialnya. Informasi online tentang fashion tampak kuat sekali dan dijadikan sumber informasi primer. Sementara mereka itu jarang sekali menggunakan sumber informasi sekunder. Dalam lingkungan sosialnya, biasanya mereka lebih memilih teman yang gadget dan fashionable sebagai sumber 
informasi.

Kata kunci: Belanja Online, Fashionable, Internet

\section{PENDAHULUAN}

Up date fasilitas perpustakaan dengan memperluas akses internet gratis tampak seperti gayung bersambut dengan semakin tingginya jumlah pengunjung perpustakaan kampus. Fasilitas layanan yang ditawarkan saat ini tidak lagi terbatas pada informasi buku teks, melainkan juga informasi digital.

Munculnya kesadaran baru akan informasi fashion di komunitas mahasiswa membangkitkan mereka untuk menjadi ingin tahu tentang trend fashion. Mereka berbondong-bondong memburu internet gratis yang difasilitasi perpustakaan fakultas. Memang diakui bahwa layanan internet gratis diadakan semenjak gedung perpustakaan pindah ke tempat yang baru. Mahasiswa tampak asik-asik menyukai layanan internet. Mereka terkadang melakukannya dengan berkelompok ataupun sendiri saja. Mereka terlihat sekali happyhappy tertawa riang kecil yang terkadang membuat noise lingkungan ruangan. Sesekali tingkah laku mereka di hadapan internet dengan tiba-tiba memekik suara dan tak jarang menjadi pusat perhatian orang sekitarnya. Tindakan mereka itu bukanlah tindakan impulsif. Mereka semangat sekali tatkala menemukan informasi yang amat dicari. Perilaku rame-rame barengbareng teman itulah perilaku mereka ketika mencari informasi internet di Perpustakaan. Perilaku demikian dikatagorikan sebagai tindakan kolektif dalam pencarian informasi di internet (collective seeking-information).
Denis McQuail (1989) sudah jauh-jauh hari mengatakan bahwa media baru internet akan membangkitkan peran perpustakaan sebagai lembaga informasi yang selama ini tidak didapatkan dari Media Massa. Peran inilah yang membuka jalan dan memberi ruang interaktif penggunanya. Media interaktif ini memikat mahasiswa untuk berkunjung ke perpustakaan kampus. Sebelumnya Lerner (1958) dalam karya yang terkenal 'The Passing of Traditional Society' mengemukakan bahwa media, khususnya internet bisa mendobrak tradisionalisme dan mendorong gerak modernitas. Ia mengatakan bahwa Internet mempertinggi harapan manusia, memberi inspirasi, memperluas wawasan, memungkinkan manusia untuk membayangkan, untuk berkhayal, dan menginginkan alternatif lebih baik bagi diri sendiri maupun lingkungannya.

Mahasiswa menyukai internet untuk mencari informasi akademik dan up date fashion. Tampilan fashion mereka memenuhi ruang-ruang layanan perpustakaan, seperti layaknya di Mall. Setiap ke kampus, mereka selalu setia mengunjungi perpustakaan untuk maksud mencari informasi fashion di internet. Perilaku pencarian informasi yang demikian ini, apakah yang disebut dengan litered atau melek informasi.

Menarik untuk dilakukan suatu penelitian yang lebih up to date tentang fenomena pencarian informasi fashion yang diakses mahasiswa melalui internet perpustakaan Kampus. Penelitian ini tidak hanya membatasi ruang kajian yang hanya fokus pada proses perilaku pencarian informasi saja, melainkan juga akan mengkaji tentang efek mengkonsumsi informasi fashion yang akan dikaitkan dengan orientasi tindakan simboliknya. 
Rumusan masalah dalam penelitian ini adalah mengamati perilaku shopping on line dan mengkaji efek mengkonsumsi informasi yang dikaitkan dengan orientasi tindakan simboliknya, yang diuraikan sebagai berikut: 1. Bagaimana proses eksplorasi informasi; 2. Bagaimana proses seleksi informasi; 3. Bagaimana proses representasi informasi; 4. Sejauhmana keterkaitan (genus proximum) faktor-faktor antasenden dengan tindakan shopping on line informasi fashion, yang kemudian dikaitkan dengan orientasi tindakan simboliknya.

Tujuan penelitian ini adalah untuk mengetahui dan menjelaskan perilaku shopping on line dan mengkaji efek mengkonsumsi informasi yang dikaitkan dengan orientasi tindakan simboliknya, yang diuraikan sebagai berikut: 1 . Untuk mengetahui dan menjelaskan aktivitas konsumen dalam eksplorasi informasi/ shopping on line; 2. Untuk mengetahui dan menjelaskan aktivitas konsumen dalam seleksi informasi/ shopping on line; 3. Untuk mengetahui dan menjelaskan aktivitas konsumen dalam representasi informasi/shopping on line; 4. Untuk mengetahui dan menjelaskan keterkaitan (genus proximum) antara faktor-faktor antasenden dengan aktivitas shopping on line, yang kemudian juga dikaitkan dengan orientasi tindakan simboliknya.

\section{TINJAUAN PUSTAKA}

Carol C. Kuhlthau (1991) dalam karyanya: 'Inside the search process: information seeking from the users perspective' menemukan enam langkah ketika seseorang mencari informasi yang diawali dari inisiasi, seleksi, eksplorasi, formulasi, koleksi, dan diakhiri dengan presentasi.
Barangkali hasil penelitian Kuhlthau ini menarik untuk dijadikan conseptual framework dalam mencari informasi fashion di internet.

Sebelumnya Wersig \& Neveling (1976) dalam karyanya: 'The phenomena of Interest to Information Science' menemukan adanya situasi problematik dalam diri seseorang ketika mencari informasi. Awalnya Wersig \& Neveling tertarik untuk meneliti tentang efek mengkonsumsi informasi. Unsur ini penting untuk diketahui karena sebagai bagian dari aktivitas manusia dalam mencari informasi. Orang mencari informasi karena ia ingin mencapai suatu kondisi yang lebih baik. Wersig \& Neveling memandang bahwa tindakan manusia mencari informasi dilandasi oleh sebuah gambaran tentang lingkungan, pengetahuan, situasi, dan tujuan yang ada dalam dirinya. Disini Wersig \& Neveling merasa penting untuk mengetahui proses pencarian informasi yang diawali dengan adanya situasi problematik dalam diri seseorang.

Sementara Carol C. Kuhlthau (1991) memandang bahwa proses pencarian informasi itu dimulai saat individu menyadari adanya kebutuhan informasi dan muncul keinginan untuk memenuhinya. Perasaan tidak yakin menyebabkan individu tersebut mengkaitkan situasi yang dihadapi dengan pengalamannya sendiri untuk merumuskan kebutuhan informasi. Dari hasil temuan-temuan tersebut, kiranya fenomena perilaku pencarian informasi masih cukup relevan dan masih memiliki ruang untuk dikaji secara interpretif. 


\section{METODE PENELITIAN}

Metode penelitian yang digunakan dalam penelitian ini adalah grounded research. Grounded merupakan penelitian kualitatif tentang fenomena yang dijelaskan dan teori yang diperolehnya secara induktif. Dalam grounded, perihal data, analisis, dan teori saling terkait dalam hubungan timbal-balik. Disini teori digunakan bukan sebagai pembatas, tetapi lebih berperan sebagai kontrol peneliti terhadap fenomena.

Grounded menempatkan analisis situasi secara kritis dan berpikir secara abstrak. Pentingnya studi lapangan untuk mengetahui apa yang terjadi. Memandang bahwa kondisi, makna, dan tindakan memiliki hubungan timbal balik. Grounded dapat memberikan prosedur untuk analisis data yang akan mengarah pada pengembangan teori.

Populasi penelitian adalah konsumen /mahasiswa yang mengakses informasi fashion melalui internet perpustakaan kampus Fakultas Ilmu Komunikasi Universitas Padjadjaran. Sampling yang digunakan adalah sampling nonpropabilitas, yakni Judgmental sampling: para konsumen informasi fashion yang mengakses informasi internet perpustakaan kampus.

Metode analisis grounded yang digunakan adalah sbb: menyusun teori, menekankan pada proses penelitian sampai menjadi teori, memberikan landasan ilmiah, memberikan kepadatan makna, mengembangkan kepekaan teori (Theoretical sensitivity) dan kesesuaian realitas yang terbaik, bukan yang tercocok. Analisis grounded dilakukan dengan menggunakan metode coding, yakni pada level open coding sampai axial coding. Open coding dan axial coding merupakan metode analisis dan prosedur yang khas dalam grounded, peneliti menggunakan keduanya secara bergantian pada saat melakukan analisis.

\section{HASIL DAN PEMBAHASAN}

\section{Infrastruktur on line}

Universitas Padjadjaran kampus Jatinangor memiliki Infrastruktur Online yang ditempatkan di beberapa titik yang berada di fakultas - fakultas yang sampai saat ini dengan bandwich yang berbeda-beda. Fakultas Ilmu Komunikasi memiliki bandwich yang lebih tinggi dibanding dengan fakultas-fakultas lainnya. Tentunya suatu hal yang logis kalau mahasiswa memberi respon positif dan mereka menyukai Infrastruktur Online gratis. Mereka memilih untuk mendekat ke perpustakaan fakultas karena memiliki Infrastruktur Online gratis, fasilitas ruang layanan yang representatif, fasilitas layanan komputer, dan layanan buku koleksi. Kelengkapan yang dimiliki perpustakaan fakultas merupakan daya tarik mahasiswa.

Intensitas kunjungan mahasiswa ke perpustakaan setidaknya satu kali dalam seminggu atau tak jarang ada juga yang dua kali dalam seminggu. Mereka setiap kali kunjungan ke perpustakaan bisa mencapai dua jam, atau ada juga yang sampai lima jam dalam menggunakan fasilitas internet kampus.

Makin tingginya minat mahasiswa berkunjung ke perpustakaan kampus ditandai oleh pemandangan di ruang - ruang layanan yang semakin tampak ramai dan crowdet, seperti layaknya keramaian di pusat-pusat perbelanjaan. Konon karena pemakaian internet yang banyak 
dalam waktu yang bersamaan, koneksi internetnya sering lemot. Mereka bersedia menunggu sampai koneksi kembali stabil, tetapi ada juga yang tak sabar menunggu. Mereka yang tak sabar menunggu memilih untuk mengakhiri aktivitas online di ruang layanan dan bergegas untuk meninggalkan perpustakaan. Mereka mencoba mencari area - area lain sekitar kampus yang menurutnya memiliki koneksi lebih bagus, atau mereka terkadang mencoba berpikir untuk menyesuaikan waktu, atau mereka akan mengakhiri aktivitas online-nya. Terkadang mereka mengalami gangguan server error saat mengakses internet. Jika terjadi adanya server error, mereka merefresh laman Web tersebut sampai bisa terbuka kembali.

\section{Product Involvement (Hal sesuatu yang berkaitan dengan produk)}

Untuk fashion baju kemeja dan kaos pria. konsumen online menyukai shopping fashion yang bergaya casual misalnya kemeja semiformal, kemeja flannel, kemeja polo, kaos polos, dan kaos oblong. Mereka mengunjungi website resmi merk - merk baju kemeja dan kaos. Mereka sebut merk dan begitu tertarik dengan sesuatu yang newness, yakni memburu produk terbaru dan terus berkeinginan untuk melakukan up date informasi.

Untuk fashion pakaian wanita. konsumen online menyukai shopping fashion yang bergaya casual dan chic. Mereka tidak mengungkapkan merk pakaian, namun memberikan kriteria seperti suka yang unik dan berwarna. Mereka juga suka up date informasi. Dalam hal kriteria, mereka sering memperhatikan saran blogernya. Mereka memiliki semacam ikatan psikologis dengan komunitas dunia maya-nya. Diakuinya bahwa pendapat dan saran komunitas dunia maya selalu mereka dengar dan memiliki kekuatan tersendiri dalam pengambilan keputusan untuk memilih produk.

Untuk gaya rambut pria. Konsumen online menyukai shopping gaya rambut yang simpel, rapi, mudah diatur, atau model rambut old school. Mereka menyukai gaya rambut yang trendy yang sedang digemari anak muda, atau sesuai kharakteristik kepribadiannya. Jika mereka hendak merubah gaya rambutnya, hampir dapat dipastikan bahwa mereka akan mencari informasi terlebih dahulu secara online. Mereka begitu memperhatikan saran yang didapat secara online, dan tampak merasa cukup puas ( presentation) dengan apa yang didapat dari informasi internet, karena banyak pilihan.

Untuk gaya rambut wanita. Konsumen online menyukai shopping gaya rambut yang memiliki belahan tengah, poni panjang, hitam berkilau, wangi, sehat, tebal dan bergelombang. Mereka juga suka tokoh idola yang melambangkan rambut idamannya. Mereka juga memiliki selera rambut yang lurus, panjang, mudah diatur, hitam, dan tebal. Menurutnya rambut lurus itu akan mudah diatur dan lebih tampak rapi. Bagi wanita tomboy, mereka menyukai gaya rambut pemain sepak bola seperti Messy dari club Barcelona; rambutnya yang hitam, potongan pendek, memiliki jambang yang tebal, dan terlihat acak-acakan.

Untuk fashion arloji pria. Konsumen online menyukai shopping arloji yang memiliki merk dan original. Mereka juga menyukai arloji 
analog, karena fungsinya yang memiliki informasi tanggal, hari, stopwatch, timer, bahkan alarm. Mereka memilih arloji yang nyaman dipakai dan tahan lama. Mereka suka up date informasi tentang merk arloji yang sedang trendy. Mereka memiliki arloji lebih dari satu dan mereka akan gunakan sesuai dengan tema pakaian.

Untuk fashion topi pria. Konsumen online menyukai shopping topi dengan melihat merk dan harga. Mereka juga memperoleh inspirasi penggunaan topi dari band idolanya. Model topi yang mereka sukai adalah model new era dan mereka mengetahui merk - merk topi seperti, Evil Army, RSCH, dan OINK. Mereka itu tidak pernah merencanakan untuk pembelian topi dan pemakaiannya disesuaikan dengan tema pakaian.

\section{Respon to Need (Respon Terhadap Kebutuhan)}

Konsumen online memiliki respon kebutuhan ganda. Kehadiran mahasiswa sebagai konsumen online di perpustakaan kampus tujuan awalnya untuk mengerjakan tugas - tugas perkuliahan dan berikutnya ( secondary) untuk shopping online informasi dunia fashion. Dalam kebiasaan perilakunya, posisi tujuan bisa mungkin terbalik, yakni sebelum mereka mencari materi perkuliahan online, mereka butuh rilek sejenak ( enjoy ) dengan melakukan aktivitas browsing ringan, seperti mencari informasi fashion. Sampai dirasa cukup, mereka akan melakukan aktivitas browsing materi perkuliahan dengan cara lebih fokus.

Mereka sepertinya memiliki level of need, yakni jika suatu informasi yang sedang ia cari ( Quarry ) itu memiliki nilai kebutuhan yang tinggi, maka mereka akan mencari informasi itu secara lebih detail, lengkap, dan memburu ( Quarry). Jika suatu informasi yang sedang ia cari itu memiliki nilai kebutuhan yang kurang, maka mereka akan mencari informasi itu sedapatnya saja ( accidental) tanpa menelusur lebih jauh.

Kedua aktivitas online tersebut mereka lakukan di ruang dan di saat waktu yang sama. Respon yang ada dalam diri mereka inilah yang barangkali bisa kita namakan sebagai respon kebutuhan ganda (double need respond). Dimana dorongan shopping online informasi fashion hampir tak dapat dipisahkan dengan aktivitas akademiknya secara online. Respon kebutuhan ganda cukup mewarnai keseharian mahasiswa konsumen online.

Menurut mereka perform diri di kampus membutuhkan dukungan dari diri sendiri seperti penampilan diri yakni suatu kebutuhan manusia akan simbolisasi. Kebutuhan inilah yang menurut Ernst Cassirer ( 1974 ) merupakan kebutuhan manusia yang istimewa, yakni animal symbolicum.

Respon kebutuhan akan baju kemeja dan kaos pria yang fashionable dan mengikuti trend terkini akan lebih menambah rasa percaya diri dan lebih nyaman. Munculnya dorongan perform yang kompetitif dilingkungan gaul juga mereka rasakan dan tak dapat mereka hindari. Mereka tidak mau dianggap ketinggalan zaman (out of date) di dalam lingkungan gaulnya. Mereka menyukai terus dan terus akan menyukai citra baru ( newness ), itu melekat pada dirinya dan itu ada pada baju kemeja, dan kaos yang mereka pakai sehari-hari di kampus. Mereka tampak respon terhadap merk. 
Berikutnya, respon kebutuhan akan fashion pakaian wanita. Mereka begitu respon terhadap sesuatu yang unik dan berwarna. Mereka kurang respon terhadap merk pakaian. Mereka begitu memperhatikan saran dari blogernya untuk hal pakaian. Sehingga saran bloger juga mendapat ruang yang istimewa di dalam diri mereka. Respon kebutuhan wanita terhadap kebutuhannya sendiri tampak cukup unik dan itu berbeda dengan respon kebutuhan pria. Wanita cenderung memiliki respon ganda yakni respon terhadap produk dan respon terhadap blogernya. Keduanya memiliki kekuatan yang sama silih berganti satu sama lainnya, walau kekuatan respon bloger sering dijadikan pertimbangan pilihan.

Respon kebutuhan akan gaya rambut pria. Mereka mengekplor model rambut yang pas dan bagus. Menurutnya, gaya rambut menunjukkan kepribadian dirinya. Sehingga mereka akan selalu mencocokan model rambut dengan kepribadian dirinya. Tak dipungkiri bahwa mereka menyukai model yang simple dan mudah diatur. Terkadang untuk pertama kali mereka memilih model rambut yang sedang trend, namun kemudian akan dicocokan dengan karakteristik dirinya. Selanjutnya, informasi internet menurutnya sudah cukup memuaskan. Mereka tampak kurang berminat untuk minta pendapat dari orang lain. Periode gaya rambut disesuaikan dengan waktu potong rambut atau berganti model. Walau mereka menyukai model yang sedang trend bagi anak - anak muda, mereka juga memiliki selera yang khas dalam memilih model rambut.

\section{Social context (Konteks sosial)}

Mereka juga mengamati model - model baju kemeja dan kaos di lingkungan gaul sosialnya secara intens dan sesekali memberikan komentar tentang penggunaan fashionnya. Mereka suka membandingkan fashion yang digunakan oleh lingkungan gaulnya dengan trend yang mereka ikuti dari media online. Informasi online tentang fashion tampak kuat dan dijadikan sumber informasi primer. Sementara mereka itu jarang sekali menggunakan sumber informasi sekunder, misal dari teman - teman mereka sendiri untuk dijadikan sebagai sumber informasi awal. Kalaupun teman mereka dijadikan sumber informasi primer tentang fashion, mereka meski menunjukkan dulu pengetahuannya secara lebih dibanding teman yang lainnya dan tentunya setelah memperoleh kepercayaan. Dalam Lingkungan gaul mereka, biasanya mereka lebih memilih teman yang gadget dan terlihat fashionable sebagai sumber informasi dan itupun mereka masih membandingkan lagi dengan informasi online.

Dalam diri mereka itu tertanam pandangan baru bahwa yang terpenting adalah bukan memakai baju barunya, tetapi yang penting bagi mereka itu adalah dapat ambil bagian untuk mengikuti trend fashion. Menggunakan baju baru bukanlah impian dan juga bukan merupakan tujuan dari up date informasi online, tetapi yang newness dan fashionable sesuai trend terkini yang sesungguhnya yang mereka buru ( Quarry). Mereka seolah patuh pada nilai sosial yang berkembang di kalangan teman - teman kampusnya dan mereka menghindari sanksi yang memberi kesan ketinggalan zaman. Suatu sanksi 
sosial yang demikianlah yang berkemungkinan akan bisa mereka rasakan sewaktu - waktu kapan saja ketika mereka bersama - sama di lingkungan kuliahnya, dan itu bisa menekan rasa percaya diri (self confident) secara mendalam bila sanksi tersebut melekat pada diri mereka.

Kebutuhan akan simbolisasi juga tampak berkembang semakin luas, bukan hanya untuk menunjang penampilan dan kepercayaan diri (self confident), namun sudah berkembang lebih luas lagi yakni berkeinginan untuk menjadi populer di lingkungannya.

\section{Keterkaitan Interpretif Shopping online} Informasi Fashion Baju Kemeja dan Kaos Pria dengan Respon Tindakan Simboliknya

Respon kebutuhan yang ada dalam diri konsumen online barangkali bisa dinamakan sebagai respon kebutuhan ganda. Dimana dorongan untuk shopping on line informasi fashion hampir tak dapat dipisahkan dengan aktivitas akademiknya secara online. Respon kebutuhan ganda cukup mewarnai keseharian konsumen online di perpustakaan kampus. Menurut pandangan mereka ; performa di kampus membutuhkan dukungan, yakni penampilan diri dan itu ada pada pakaian kemeja dan kaos. Dengan tampilan kemeja dan kaos yang fashionable dan mengikuti trend terkini akan lebih merasa percaya diri dan lebih nyaman. Munculnya dorongan untuk perform diri dilingkungan gaulnya juga mereka rasakan dan tak dapat mereka hindari, bahkan cenderung kompetitif. Mereka memposisikan tidak mau dianggap ketinggalan zaman (out of date) di dalam lingkungan gaulnya. Mereka menyukai terus dan terus akan menyukai citra baru itu melekat pada dirinya dan itu ada pada pakaian kemeja dan kaos. Pakaian yang mereka pakai sehari-hari di kampus. Kontak sekunder yang dilakukan oleh konsumen online tampak berlanjut pada kontak primer, yakni kontak sesama teman di lingkungan kampus. Kontak primer tampak semakin intens dilakukan dan menunjukkan tanda-tanda yang meningkat, baik secara kuantitas maupun kualitas. Kehadiran internet tak dapat terbantahkan bahwa kehadirannya membawa konsekuensi pada pola hubungan antar mahasiswa di kampus.

Charles H. Cooly ( 1930 ) dalam karya bukunya yang berjudul : 'Sociological Theory and Social Research' mengatakan bahwa interaksi itu timbul apabila orang menyadari bahwa mereka mempunyai kepentingan - kepentingan yang sama, dan pada saat yang bersamaan mempunyai cukup pengetahuan. Artinya bahwa interaksi itu membutuhkan pengetahuan yang cukup. Jika pengetahuan mereka tidak cukup, maka akan sulit terjadi interaksi dengan baik, apalagi akan terjadi peningkatan interaksi.

Charles H. Cooly tampaknya menekankan adanya peningkatan volume pengetahuan pada diri individu untuk mewujudkan interaksi yang lebih, yakni interaksi individu dengan individu, maupun individu dengan kelompok. Meningkatnya suplai pengetahuan melalui kontak sekunder tidak akan menurunkan kualitas interaksi kontak primer, justru sebaliknya akan juga meningkatkan kualitas interaksi primer. Individu - individu sudah memiliki ruang dan waktu untuk melakukan kotak sekunder maupun kontak primer. Meningkatnya Interaksi kontak sekunder melalui online mengantarkan mereka pada penambahan 
pengetahuan, bukan pengurangan pengetahuan. Bertambahnya ruang pengetahuan individu mengantarkan pada perluasan ruang interaksi primer dan akan muncul diketahui pada respon kebutuhan, yang sebelumnya tidak mereka dapatkan.

Shopping online informasi fashion kemeja dan kaos pria membuka ruang baru pada interaksi primer di lingkungan kampus. Pengetahuan mereka telah mengantarkan pada dunia baru, yakni dunia fashion. Mereka awalnya hanya ingin memiliki penampilan diri yang fashionable di kampus, guna mendongkrak rasa percaya diri lebih sempurna. Namun dalam perkembangannya, tampil fashionable di lingkungan kampus merupakan suatu kebutuhan yang sulit ditawartawar lagi, dan melahirkan suatu ikatan sosial dan bahkan sanksi sosial. Mereka ingin tampil newness setiap kali bertemu dengan temantemannya di kampus. Mereka sangat menghindari penampilan yang ketinggalan zaman (out of date), kalau tak mau diperolok atau mendapat labelling. Mereka ingin tampil keren dimata temantemannya di kampus. Penampilan citra keren terus mereka jaga dan pertahankan. Upaya up date informasi fashion tak dapat lagi mereka hindari dan terus mereka lakukan melalui shopping online informasi fashion. Sehingga citra keren dimata mahasiswa merupakan orientasi baru dalam tindakan simboliknya.

Ernst Cassirer mengatakan bahwa 'keunggulan manusia atas makhluk lainnya adalah keistimewaan mereka sebagai animal symbolicum'. Selanjutnya dipertegas lagi oleh Susanne K. Langer yang mengatakan bahwa 'salah satu kebutuhan pokok manusia adalah kebutuhan akan simbolisasi'. Simbol itu merupakan sesuatu yang dapat digunakan untuk menunjuk sesuatu lainnya, berdasarkan kesepakatan dalam kelompok ( Shrope, 1974 ). Jika demikian, kebutuhan akan simbolisasi keren merupakan kebutuhan pokok mahasiswa yang terstimuli oleh hasil kontak sekunder melalui media online, yang saat ini mereka aplikasikan dalam orientasi tindakan sosial dalam ruang kontak primer komunitas mereka. Munculnya kebutuhan pokok akan fashion kemeja dan kaos memiliki kaitan yang erat (genus proximum) dengan hasil interaksi mereka di ruang media online. Penambahan pengetahuan akan fashion mereka peroleh dengan mudah melalui kontak sekunder. Disini penambahan pengetahuan akan fashion memiliki keterkaitan dengan respon kebutuhannya, yakni kebutuhan akan simbolisasi. Disini dapat dikatakan bahwa respon kebutuhan akan simbolisasi merupakan langkah awal atau yang mengawali mereka, atau yang menggerakkan mereka untuk beraktivitas sekunder melalui media online. Ruang aktivitas sekunder melalui media online itu mereka rasakan lebih bisa terjangkau dibandingkan dengan melalui ruang primer, atau mereka memilih ruang sekunder itu karena cocok untuk dijadikan sumber informasi. Disini jika kita amati lebih cermat lagi, maka kita akan memperoleh jawaban yang lebih jelas lagi bahwa mereka percaya ( belief) dengan sumber informasi online. Unsur belief inilah yang menggerakkan mereka untuk up date informasi melalui media online. Jadi mereka memilih interaksi sekunder dalam memdapatkan sumber informasi, bukan yang berasal dari interaksi primer. 
Dalam hubungannya dengan budaya (culture) suatu komunitas atau subculture, maka kebudayaan itu yang mengarahkan dan mendorong terjadinya kompetisi. Apabila individu dihinggapi oleh suatu perasaan kurang percaya diri bahwa posisinya itu lebih rendah, maka ia hanya menginginkan posisi yang sederajat, bukan posisi yang lain. Individu - individu yang mempunyai rasa kurang percaya diri yang tebal memiliki kecenderungan yang sangat kuat sekali dalam mengejar posisi yang sederajat tersebut. Hal ini sebagai konsekuensi dari rasa kurang percaya dirinya tersebut. Posisi apa yang dikejar, tergantung daripada yang paling dihargai oleh komunitas dan memiliki masa tertentu (Soekanto, 1982). Posisi keren merupakan posisi yang diinginkan komunitas, karena itu mahasiswa akan menginginkan penampilan yang keren dalam komunitasnya. Kompetisi yang terjadi adalah untuk mendapatkan predikat keren dimata komunitas.

John L. Gillin \& John P. Gillin ( 1954 ) dalam karya bukunya yang berjudul : 'Cultural Sociology' memahami interaksi dalam konteks yang lebih luas, yakni suatu proses sosial. Sehingga kompetisi bisa diartikan sebagai suatu proses sosial, dimana individu - individu atau kelompok yang berkompetisi mencari keuntungan melalui bidang - bidang kehidupan yang pada suatu masa tertentu menjadi pusat perhatiannya, yakni dalam hal ini adalah predikat keren, dengan mempertajam prasangka atau memberlakukan sanksi sosial yang sudah 'disepakati' dan berkembang dilingkungan mahasiswa kampus. Walau kompetisi yang berkembang bersifat pribadi, akan tetapi nantinya tidak akan sampai menjadi rival-ry. Mereka hanya pada pencapaian posisi keren di komunitas, bukan pencapaian peran dalam sebuah organisasi. Jadi kompetisi masih akan tampak berlangsung terkendali dan tanpa adanya konflik fisik, karena yang mendapatkan predikat keren bisa banyak orang, bukan satu orang saja.

\section{Keterkaitan Respon Tindakan Simbolik} Customer Dengan Munculnya Stratifikasi Pada Subculture di Lingkungan Kampus

Keinginan menjadi populer dengan tampil newness dan fashionable di kalangan rekan mahasiswa kampus merupakan fenomena menarik di kalangan mahasiswa pria, setelah hadirnya informasi internet gratis di perpustakaan kampus. Mereka ingin menjadi populer dengan mengakses informasi online tentang fashion baju kemeja dan kaos. Kalaupun mereka awalnya mengkonsumsi informasi fashion online untuk maksud mendongkrak penampilan dan rasa percaya diri, ternyata sekarang maksud mengkonsumsi informasi sudah berkembang lebih luas lagi, yakni untuk maksud memperjuangkan popularitas.

Masih banyak mahasiswa tampil dan berbusana karena kebiasaan saja, karena itulah cara orang tua mereka berpakaian. Mereka sering kritis terhadap cara berpakaian orang lain yang berbeda dengan cara mereka, namun mereka tidak pernah bertanya mengapa mereka sendiri berpakaian seperti yang mereka lakukan. Selanjutnya dalam catatan Mulyana (2007) dapat kita ketahui bahwa sudah berabad-abad para orang tua anggota kerajaan telah menunjukkan status mereka melalui pakaian anak-anaknya. Akan tetapi ada juga yang berpandangan bahwa 
pilihan seseorang atas pakaian mencerminkan kepribadiannya, dan digunakan untuk memproyeksikannya citra tertentu yang diinginkan pemakainya. Bahkan dalam bahasa Latin sudah dikenal adanya suatu istilah 'Uestis uirum reddit' yang artinya 'pakaian menjadikan orang atau pakaian adalah orang'. Mereka berpakaian bukan sekedar untuk menutupi tubuh atau asal pantas, namun juga berusaha menciptakan kesan yang lebih pada orang lain.

Pitirim A. Sorokin dalam karya bukunya yang berjudul : 'Contemporary Sociological Theories' memandang bahwa 'selama itu dalam suatu subculture ada sesuatu yang dihargai, dan setiap subculture pasti memiliki sesuatu yang dihargai, maka hal itu akan menjadi embrio yang dapat menumbuhkan adanya stratifikasi Soekanto, 1982 ). Pemakaian fashion baju kemeja dan kaos di lingkungan kampus, bagi kaum lakilaki barangkali merupakan suatu pilihan yang mereka hargai, walau awalnya sekedar untuk mendongkrak penampilan dan rasa percaya diri.

Bentuk - bentuk strata dalam subculture itu berbeda-beda dan banyak sekali bentuknya, akan tetapi strata-strata tersebut tetap tampak ada. Strata - strata itu sudah ada sejak manusia mengenal adanya kehidupan bersama di dalam masyarakat sosial. Stratifikasi bisa terjadi dengan sendirinya dalam proses pertumbuhan subculture itu sendiri, tetapi ada pula stratifikasi dalam subculture yang dengan sengaja disusun untuk mengejar suatu tujuan. Dalam proses pertumbuhan gaul antar mahasiswa di kampus, fashion baju kemeja dan kaos awalnya tampak tumbuh dengan sendirinya dalam proses pergaulannya. Akan tetapi dalam perkembangannya bisa saja memiliki kemungkinan adanya proses penciptaan oleh anggota subculture, dan disadari atau tidak disadari mereka itu 'sepakat' untuk memberi ruang yang lebih luas lagi, yakni mengejar popularitas.

Fenomena mengejar popularitas pada lingkungan subculture dapat mungkin terjadi pada lingkungan yang terbuka ( open social stratification ), bukan lingkungan yang tertutup (closed social stratification). Pada lingkungan yang terbuka, setiap anggota subculture memiliki peluang kesempatan yang sama untuk berusaha dengan kecakapannya sendiri untuk memperoleh kedudukan yang lebih tinggi, atau mereka bisa jatuh ke posisi bawah. Karena itu up date informasi terus mereka lakukan dan media yang mereka pilih dan dianggap terpercaya adalah media online, bukan lagi media person to person. Mereka dari hari ke hari, dari minggu ke minggu tetap terus mempertahankan kesimbangan dengan cara up date informasi melalui media online di perpustakaan kampus. Sehingga dapat dikatakan bahwa mereka itu sesungguhnya mengejar status yang dinamakan 'achieved status'.

\section{SIMPULAN}

Mahasiswa memberikan respon welcoming atas kehadiran Infrastruktur Online gratis. Mereka memilih untuk mendekat ke perpustakaan fakultas untuk memanfaatkan waktu di kampus. Mereka tampak senang dengan adanya Infrastruktur Online gratis.

Kelengkapan yang dimiliki perpustakaan fakultas saat ini merupakan daya tarik tersendiri bagi mahasiswa. Intensitas kunjungan mahasiswa 
ke perpustakaan selalu hadir dalam seminggu. Setiap kali kunjungan ke perpustakaan bisa mencapai dua jam atau lebih dalam menggunakan fasilitas internet kampus.

Ruang-ruang layanan yang semakin tampak ramai dan crowdet. Konon karena pemakaian yang banyak dalam waktu yang bersamaan, koneksi internetnya sering lemot. Bagaimanapun mereka bersedia menunggu sampai koneksi kembali stabil. Ada juga yang tak sabar menunggu. Mereka yang tak sabar menunggu biasanya memilih untuk mengakhiri aktivitas online dan bergegas meninggalkan perpustakaan. Mereka mencoba mencari area area lain yang menurutnya memiliki koneksi bagus, atau mereka terkadang mencoba berpikir untuk menyesuaikan waktu dimana yang tidak banyak orang mengakses.

Untuk hal sesuatu yang berkaitan dengan produk sbb: Untuk fashion baju kemeja dan kaos pria. Konsumen online menyukai shopping yang bergaya casual. Mereka mengunjungi website resmi merk - merk baju kemeja dan kaos. Mereka begitu tertarik dengan merk dan newness.

Khusus fashion pakaian wanita. Konsumen online menyukai shopping bergaya casual dan chic. Konsumen jarang mengungkapkan merk pakaian, namun mereka memberikan kriteria seperti suka yang unik dan berwarna. Dalam hal kriteria, mereka juga memperhatikan saran-saran dari blogernya. Mereka memiliki semacam ikatan psikologis yang cukup kuat dengan groupnya. Bahwa pendapat dan saran group selalu mereka dengar dan memiliki kekuatan tersendiri dalam pengambilan keputusan memilih suatu produk.
Untuk gaya rambut pria. Konsumen online menyukai shopping gaya rambut yang simpel dan mudah diatur, misal model rambut old school. Mereka menyukai gaya rambut trendy yang sedang digemari anak muda sekarang, dan disesuaikan dengan kharakteristik kepribadian dan selera. Jika mereka hendak merubah gaya rambutnya, hampir dapat dipastikan bahwa mereka akan mencari informasi terlebih dahulu secara online. Mereka begitu memperhatikan rekomendasi yang didapat secara online, dan tampak merasa cukup puas ( presentation ) dengan apa yang didapat dari informasi internet.

Untuk gaya rambut wanita. Konsumen online menyukai shopping gaya rambut yang memiliki belahan tengah, poni panjang, hitam berkilau, wangi, sehat, tebal dan bergelombang. Mereka juga suka tokoh idola yang melambangkan rambut idamannya. Mereka juga memiliki selera rambut yang lurus, panjang, mudah diatur, hitam, dan tebal. Menurutnya rambut lurus itu akan mudah diatur dan lebih tampak rapi.

Untuk fashion arloji pria. Konsumen online menyukai shopping arloji yang memiliki merk dan original. Mereka menyukai arloji analog, karena fungsinya yang memiliki informasi tanggal, hari, stopwatch, timer, bahkan alarm. Mereka memilih arloji yang nyaman dipakai dan tahan lama. Mereka suka up date informasi tentang merk arloji yang sedang trendy. Mereka memiliki arloji lebih dari satu dan mereka akan gunakan sesuai dengan tema pakaian.

Untuk fashion topi pria. Konsumen online menyukai shopping topi dengan melihat merk dan harga. Mereka juga memperoleh inspirasi 
penggunaan topi dari idolanya. Model topi yang mereka sukai adalah model new dan mereka mengetahui merk - merk topi. Mereka itu tidak pernah merencanakan untuk pembelian topi dan pemakaiannya disesuaikan dengan tema pakaian. Baginya topi merupakan asesoris yang melekat pada dirinya.

Respon terhadap kebutuhan (respon to need). Konsumen online memiliki respon kebutuhan ganda. Kehadiran mahasiswa sebagai konsumen online di perpustakaan kampus tujuan awalnya untuk mengerjakan tugas - tugas perkuliahan dan selanjutnya (secondary) untuk shopping online informasi dunia fashion. Dalam kebiasaan perilakunya (information behavior), posisi tujuan bisa mungkin terbalik, yakni sebelum mereka mencari materi perkuliahan online, mereka terlebih dahulu butuh rilek sejenak (enjoy) dengan melakukan aktivitas browsing, seperti mencari informasi fashion. Sampai dirasa cukup, mereka akan melakukan aktivitas browsing materi perkuliahan dengan cara lebih fokus.

Mereka memiliki level of need, yakni jika suatu informasi yang sedang ia cari itu memiliki nilai kebutuhan yang tinggi, maka mereka akan mencari informasi itu secara lebih detail, lengkap, dan memburu (Quarry). Jika suatu informasi yang sedang ia cari itu memiliki nilai kebutuhan yang kurang, maka mereka akan mencari informasi itu sedapatnya saja tanpa menelusur lebih jauh.

Respon kebutuhan akan baju kemeja dan kaos pria yang fashionable dan mengikuti trend terkini akan lebih menambah rasa percaya diri dan lebih nyaman. Munculnya dorongan perform yang kompetitif dilingkungan gaul juga mereka rasakan dan tak dapat mereka hindari. Mereka tidak mau dianggap ketinggalan zaman ( out of date ) di dalam lingkungan gaulnya. Mereka menyukai terus dan terus akan menyukai citra baru ( newness ), itu melekat pada dirinya dan itu ada pada baju kemeja dan kaos, pakaian yang mereka pakai sehari-hari di kampus. Mereka tampak respon terhadap merk baju kemeja dan kaos.

Respon kebutuhan akan fashion pakaian wanita. Mereka begitu respon terhadap sesuatu yang unik dan berwarna. Mereka kurang respon terhadap merk pakaian. Mereka begitu memperhatikan saran - saran dari blogernya untuk hal pakaian, sehingga saran-saran bloger juga mendapat ruang yang istimewa di dalam diri mereka. Respon kebutuhan wanita terhadap kebutuhannya sendiri tampak cukup unik dan itu berbeda dengan respon kebutuhan pria. Wanita cenderung memiliki respon ganda yakni respon terhadap produk dan respon terhadap teman blogernya, khususnya wanita. Keduanya memiliki kekuatan yang sama, silih berganti satu sama lainnya, walau kekuatan respon bloger wanita yang sering dijadikan pertimbangan pilihan.

Respon kebutuhan akan gaya rambut pria. Mereka mengekplor model rambut yang benar benar pas dan bagus. Menurutnya, gaya rambut menunjukkan kepribadian dirinya. Sehingga mereka akan selalu mencocokan model - model rambut dengan dirinya, dan terkadang membutuhkan waktu yang cukup lama untuk mengamati dan mencocokan. Tak dipungkiri bahwa mereka menyukai model yang simple dan mudah diatur. Mereka tampak kurang berminat untuk minta pendapat dari orang lain. Periode gaya rambut, biasanya disesuaikan dengan waktu potong rambut atau berganti model. Walau 
mereka menyukai model yang sedang trend, tetapi mereka juga memiliki selera yang khas dalam memilih model rambut.

Mereka juga mengamati model - model baju kemeja dan kaos di lingkungan gaul sosialnya secara intens dan sesekali memberikan komentar tentang penggunaan fashionnya. Mereka suka membandingkan fashion yang digunakan oleh lingkungan gaulnya dengan trend - tred yang mereka ikuti dari media online. Informasi online tentang fashion tampak kuat sekali dan dijadikan sumber informasi primer. Sementara mereka itu jarang sekali menggunakan sumber informasi sekunder, misal dari teman - teman mereka sendiri. Dalam Lingkungan gaul mereka, biasanya mereka lebih memilih teman yang gadget dan terlihat fashionable sebagai sumber informasi dan itupun mereka masih membandingkan lagi dengan informasi online. Disini tampak bahwa informasi online adalah number one.

Dalam diri mereka itu tertanam pandangan baru bahwa yang terpenting adalah bukan memakai baju barunya, tetapi yang penting bagi mereka itu adalah dapat ambil bagian untuk mengikuti trend fashion. Menggunakan baju baru bukanlah impian dan juga bukan merupakan tujuan dari up date informasi online, tetapi yang newness dan fashionable sesuai trend terkini yang sesungguhnya yang mereka buru ( Quarry). Mereka seolah patuh pada nilai sosial yang berkembang di kalangan teman - teman mahasiswa kampusnya dan mereka menghindari sanksi yang memberi kesan ketinggalan zaman. Suatu sanksi sosial yang demikianlah yang berkemungkinan akan bisa mereka rasakan sewaktu - waktu kapan saja ketika mereka bersama - sama di lingkungan kuliahnya, dan itu bisa menekan rasa percaya diri secara mendalam bila sanksi tersebut sampai melekat pada diri mereka. Kebutuhan akan simbolisasi juga tampak berkembang semakin luas, bukan hanya untuk menunjang penampilan dan kepercayaan diri (self confident), namun sudah berkembang lebih luas lagi, yakni berkeinginan untuk menjadi populer di lingkungan sosialnya.

\section{DAFTAR PUSTAKA}

Anselm, Strauss dan Juliet Corbin. (2003). Dasardasar Penelitian Kualitatif. Yogyakarta: Pustaka Pelajar.

Babbie, Earl R. (1986). The of Social Research. Belmont, Calif: Wadshworth Pub.Co.

Belkin, Nicholas J dan A Vickery. (1985). Interaction in Information Systems: a Review of Research from Document Retrieval to Knowledge-Based Systems. London: British Library.

Corbin, Juliet. (1987). Grounded Theory Methodology: An Overview.

Harter, Stephen P. (1992). Psychological Relevance and Information Science.Journal of the American Society for Science. Vol.43 (9) pp. 602-615.

Kuhlthau, Carol C. (1991). Inside the Search Process: Information Seeking From The Users Prespective. Journal of The American Society for Information Science, Vol.42 (5). pp.361-371

Lerner, Daniel. (1958). The Passing of Traditional Society: Modernizing the Middle East. Glencoe; Free Press.

McQuail, Denis. (1989). Teori Komunikasi Massa: Suatu Pengantar. Jakarta: Erlangga.

Singarimbun, Masri dan Soifan Efendi (Ed.). (1989). Metode Penelitian Survai. Jakarta: LP3ES.

Wersig, Gemot dan Ulrich Neveling. (1976). The Phenomena of Interest to Information Science. Information Scientist Vol.9 (4) pp.127-140. 
